\title{
The Magnetic Protection of Cooling System in Internal Combustion Engines Against Corrosion and Scale Formation
}

\author{
${ }^{1} \mathrm{M}$. Gholizadeh and ${ }^{2} \mathrm{H}$. Arabshahi \\ ${ }^{1}$ Department of Chemistry, ${ }^{2}$ Department of Physics, \\ Ferdowsi University of Mashhad, Mashhad, Iran
}

\begin{abstract}
The effect of magnetism on the internal scale formation responsible for pitting corrosion inside the engine's cooling jackets have been studied. It is found that the presence of permanent magnetic field inhibits scale formation and protects the cooling systems in petrol and diesel engines from internal corrosion.
\end{abstract}

Key words: Magnetism, corrosion, scale formation, magnetic field, petrol, diesal

\section{INTRODUCTION}

The presence of insoluble salts of $\mathrm{Ca}^{2+}$ and $\mathrm{Mg}^{2+}$ ions in water leads to frequent sedimentation resulting in scale formation inside the cooling system of internal combustion of engines and hence internal corrosion. Initially fine pits appear inside the engine's cooling jackets then spotted corrosion starts and finally the jacket corrodes uniformly from inside.

At present, various methods of scale prevention have been developed and introduced (Baker and Parsons, 1996; Welder and Partridge, 1954; Pilipenko, 1991). For example, in some machines the additives is mixed with water for prevention against scale and corrosion formation in the engine's cooling jackets and cooling system radiators. However, this water treatment method requires high power consumption. Water quality was being continuously monitored whilst the engine was in operation and was not very environmentally friendly, either. Previous experiments have also been shown that precipitation of insoluble calcium salts increases with the rise in temperature of water and the $\mathrm{PH}$ changes accordingly. With increasing water temperature the concentration of insoluble salts increases and the $\mathrm{CO}_{2}$ gas is released from $\mathrm{CaCO}_{3}$ as can be seen from the following sequence:

$$
\begin{aligned}
& 2 \mathrm{HCO}_{3}^{-} \rightarrow \mathrm{CO}_{3}^{2-}+\mathrm{CO}_{2}+\mathrm{H}_{2} \mathrm{O} \\
& \mathrm{Ca}^{2+}+\mathrm{CO}_{3}^{2-} \rightarrow \mathrm{CaCO}_{3} \text { (calcite) } \\
& \mathrm{Ca}^{2}+\mathrm{CO}_{3}^{2-} \rightarrow \mathrm{CaCO}_{3} \text { (aragonite) }
\end{aligned}
$$

This also increases the $\mathrm{pH}$ value of water. For example at $\mathrm{pH}=7$, water at zero temperature can hold $185 \mathrm{mg} \mathrm{L}^{-1}$ of $\mathrm{Ca}^{2+}$ as $\mathrm{Co}_{3}{ }^{2-}$ before actually precipitation take place. At higher temperature, for example, $100^{\circ} \mathrm{C}$ it can hold only $25 \mathrm{mg} \mathrm{L}^{-1}$.

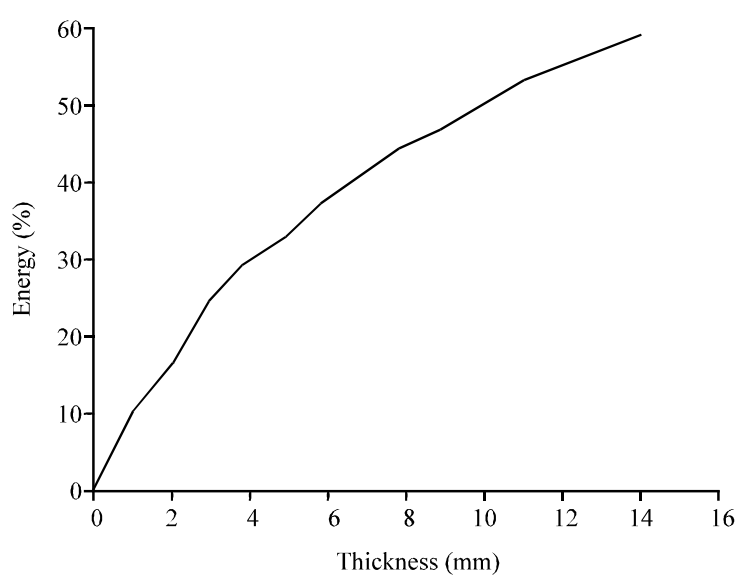

Fig. 1: The curve of energy consumption versus thickness

At $\mathrm{pH}=11$, water at zero temperature holds $<10 \mathrm{mg} \mathrm{L}^{-1}$ and at $60^{\circ} \mathrm{C}$ it holds $210 \mathrm{mg} \mathrm{L}^{-1}$. This means that water attains extremely high dissolving ability for calcium salts at high $\mathrm{pH}$ values.

Another experiment has also shown that if the precipitated thickness of insoluble calcium salts or the other scales grew to $0.1 \mathrm{inch}$, it would decrease the heat transfer at cooling system to the level of $38 \%$ (Fig. 1) (Aaron, 1990).

The employment of a new technology to prevent the build-up unwanted lime scale is necessary. One of the new method which can be used is a physical water treatment, a process where some of the components of water show altered crystalline behavior after flowing through a magnetic field (magnetic technology) (Baker and Parsons, 1996; Welder and Partridge, 1954; Eshaghi and Gholizadeh, 2004). The general operating principle for the magnetic technology is a result of the

Corresponding Author: M. Gholizadeh, Department of Chemistry, Ferdowsi University of Mashhad, Mashhad, Iran 


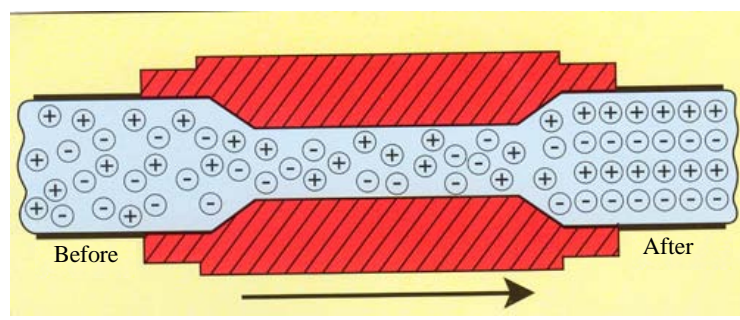

Fig. 2: Configuration of electrons in magnetic field

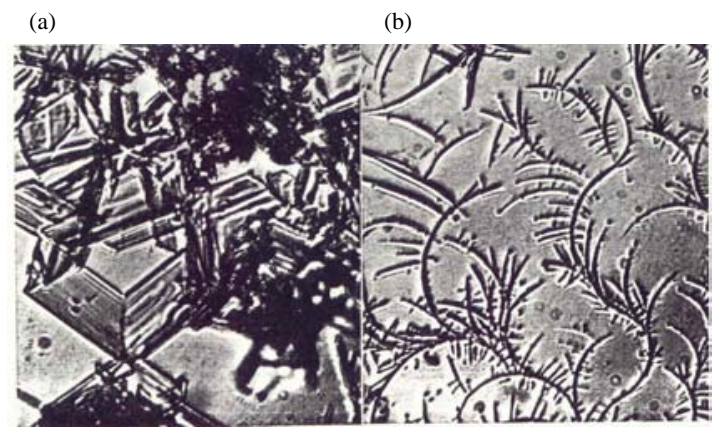

Fig. 3: a) Microscopic representation of calcium carbonate crystals in water which is not filtered (magnified 600 times); b) Microscopic representation of calcium carbonate crystals in magnetic water (magnified 600 time)

physics of interaction between a magnetic field and a moving electric charge, in this case in the form of an ion. When ions pass through the magnetic field, a force is exerted on each ion. The forces on ions of opposite charges are in opposite directions (Fig. 2). The redirection of the particles tends to increase the frequency with which ions of opposite charge collide and combine to form a mineral precipitate, or insoluble compound.

Since this reaction takes place in a low-temperature region of a heat exchange system, the scale formed is non-adherent. At the prevailing temperature conditions, this form is preferred over the adherent form which attaches to heat exchange surfaces.

The operating principles for the electrostatic units are much different. Instead of causing the dissolved ions to come together and form non-adherent scale, a surface charge is imposed on the ions so that they repel instead of attract each other. Thus the two ions (positive and negative or cations and anions, respectively) of a kind needed to form scale are never able to come close enough together to initiate the scale-forming reaction (Fig. 3). The end result for a user is the same with either technology; scale formation on heat exchange surfaces is greatly reduced or eliminated (Gholizadeh et al., 2005).

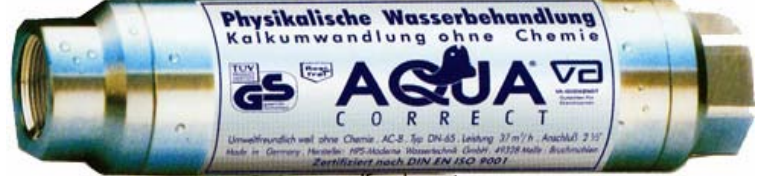

Fig. 4: The magnetic instrument and stainless steel strainer

Table 1: The change of mass percentages of crystal forms of calcium carbonate due to magnetic water treatment

\begin{tabular}{lccc}
\hline Crystal forms of $\mathrm{CaCO}_{3}$ & Calcite (\%) & Aragonite (\%) & Vatriete (\%) \\
\hline Magnetic water & 14 & 44 & 42 \\
Non-magnetic water & 34 & 14 & 52
\end{tabular}

Experiment: To have a permanent magnet in a compact form, a unit called Aqua Correct is used. This equipment has a coaxial permanent system which can produce a magnetic field strength as high as $1.2 \mathrm{~T}$. Aqua Correct has a free and smooth internal flow which exclude the presence of turbulence (Strum and Morgan, 1940). The function is pure magnetic physical. So the crystal structure of lime scale will change and can easily remove it. A stainless steel strainer was used before this instrument (Fig. 4).

The equipment was connected to the engine's cooling system from one end to the radiator and the other end to the water pump. Before installation, conditions of the engine's cooling system as well as the physical and chemical properties of water were carefully studied. Since water had to flow through a coaxial permanent magnetic gap, the flow rate of water was checked before installation. The direction of the flow of water was adjusted to be perpendicular to the field.

A stainless steel wire net was placed inside the equipment to capture the suspended impurities present in water. About 30 days after installation, the filter was checked.

The flow rate and conditions of the engine's circulating system were restudied. Every 3 months there after the filter of engine's cooling system was opened and studied. After 1 year, final observations were made with respect to the internal conditions of the engine's cooling system and the results of Table 1 in the next section have been carried out.

\section{RESULTS AND DISCUSSION}

Using water magnetic treatment technology shows no traces of corrosion or scale deposits on the surface of the cylinder cooling jackets, pipelines and radiators. The jackets were covered with a film of $<4$ microns of magnetite $\left(\mathrm{Fe}_{3} \mathrm{O}_{4}\right)$ exhibiting anti-corrosive properties. Magnetite has formed, under the action of the electromotive force within the magnetic apparatus 


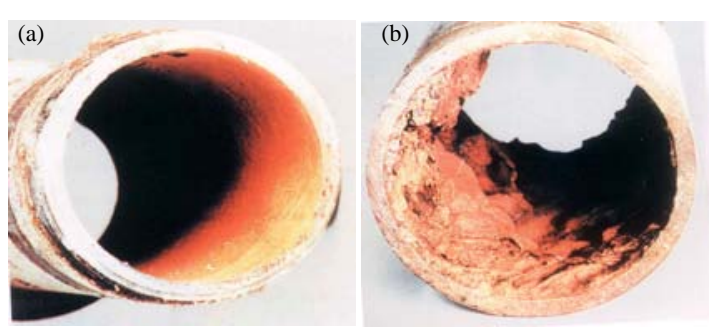

Fig. 5: a) After installation the magnetic apparatus; b) Before installation the magnetic apparatus

medium. Electrons circulating in the cooling system polarized the metal surface negatively and uniformly. As a result of polarizing a partial transformation of Iron oxide to Iron Prooxide take place; consequently, magnetite is formed. When the magnetic apparatus was placed in the cooling system of a petrol engine with scale deposits, it dissolved the scales. This is due to the fact that the volume of magnetite formed is less than the volume of the existing iron oxide or rust. Under the influence of heat, evaporation of water and expansion of different gases take place which eventually leads to the swelling and subsequent dissolution of scale. Water samples taken after the flow of water through the magnetic apparatus revealed the existence of scale, ranging in thickness between 0.5 and 5 microns.

The experiment shows that the new magnetic system fitted with the Aqua Correct can well protect the system from scale formation and internal corrosion whereas the engine's cooling system without the equipment was badly damaged by scale formation and internal corrosion occurring inside the engine's cooling system (Fig. 5). Also, it is shown that after installation of the magnetic instrument on the cooling system the cooling jackets and pipelines system were automatically cleared and the solid material became loose and fell off. Thus, the life span of the car's cooling system could be increased. The results from X-ray analysis showed that there was a difference in the amount of the two crystallographic forms of $\mathrm{CaCO}_{3}$ if the model water was treated with a magnetic field which is in fair agreement with Coey and Cass (2000) experimental results (Table 1).

The results show that the ratio of Aragonite/Calcite is remarkably has been increased in the magnetic water treatment. Therefore, the presence of the magnetic field changes the direction of the crystal growth to the Aragonite which is a softer type of scale and less likely to form an adhesive scale which can be easily removed. Over 1 year of research with magnetic water the following results have also been carried out:

- The Aqua Correct, never affected the properties of the ordinary water and $\mathrm{pH}$ had no effect on the scale formation due to the use of the equipment

- Turbulence can not decrease the properties of magnetic water because after flowing through a magnetic field, the magnetization properties will be saved over $200 \mathrm{~h}$

- The best magnetic field strength is about 0.6-1 T with a water flowing of $0.1 \mathrm{msec}^{-1}$ which can produce by water pump

\section{CONCLUSION}

Test results after 1 year showed that Aqua Correct works satisfactory and if fitted to the cooling system of a new car, the life span of the cooling system could be increased. The jacket of cooling system also could be well protected from scale formation and corrosion as the scale formation is avoided by the magnetic field.

\section{REFERENCES}

Baker, J.S. and S.A. Parsons, 1996. Anti-scale magnetic treatment. Water Waste Treatment, 39: 36-38.

Coey, J.M.D. and S. Cass, 2000. Magnetic water treatment. J. Magnetism Magn. Mater., 209: 71-74.

Eshaghi, Z. and M. Gholizadeh, 2004. The effect of magnetic field on the stability of (18-crown-6) complexes with potassium ion. Talenta, 64: 558-561.

Gholizadeh, M., H. Arabshahi and M.R. Benam, 2005. The effect of magnetic field on scale prevention in the industrial boilers. Int. J. Applied Chem., 1: 84-89.

Pilipenko, A.T., 1991. Methods of scale preventation in desalination of saline waters. Khimiyai. Technologiya Vody, 13: 996-996.

Strum, W. and J.P. Morgan, 1940. Aquatic Chemistry. Wiley-Interscience, New York.

Welder, B.Q. and E.P. Partridge, 1954. Practical performance of water-conditioning gadgets. Ind. Eng. Chem., 46: 954-960. 